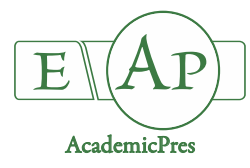

\title{
Bagging Affecting Sugar and Anthocyanin Metabolism in the Ripening Period of Grape Berries
}

\author{
Qian ZHA, Xiao Jun XI, Yani HE, Ai Li JIANG* \\ Research Institute of Forestry and Pomology, Shanghai Key Lab of Protected Horticultural Technology, Shanghai Academy of Agricultural \\ Sciences,Shanghai 201403,China; zhaqian1988@163.com;xxj220401@126.com; heyani1113@163.com; \\ putaojal@163.com (*correspondingauthor)
}

\begin{abstract}
Grapevine is one of the most important fruit-bearing plants worldwide, for which bagging treatments can effectively improve fruit quality. However, the low-light conditions caused by bagging can delay grape berry maturation. Here, we analyzed glucose, fructose, and anthocyanin contents and the expression of sugar and anthocyanin-metabolism pathway genes in the grape berries of two cultivars, 'Shenhua' and 'Shenfeng', under different bagging treatments. Color development was incomplete in bagged grape berries and their soluble sugar contents were lower than those detected in un-bagged fruits. However, fruit color and SSC could be rapidly restored to normal levels after removing bags. Light affects the accumulation of sugar in grape berries, especially near the maturation period, as well as the contents and compositions of anthocyanins in the skin of grape berries. Although light helps in the accumulation of anthocyanins, significant differences were detected in anthocyanin composition between the two grapevine varieties. In addition, the expressions of myofibroblastic regulatory genes in the anthocyanin pathway were affected by light, and the light-responsive elements elongated hypocotyl 5 and constitutive photomorphogenic 1 acted synergistically to control grape berry coloration. Overall, these results provide a theoretical basis for the maturation mechanism in grape berries.
\end{abstract}

Keywords: fructose; glucose; grapevine; light stress

Abbreviations: ANS: Anthocyanidin synthase; CHI: Chalcone isomerase; CHS: Chalcone synthase; CIRG: Color index of red grape; COP: Constitutive photomorphogenic; DFR: Dihydroflavonol 4-reductase; DAA: Day after anthesis; F3H: Flavanone-3-hydroxylase; HPLC: High-performance liquid chromatography; HY: Hypocotyl ; MYB: Myofibroblastic; TA: Titratable acidity; SSC: Total soluble solid content

\section{Introduction}

Grapevine is grown extensively throughout the world. In 2014, worldwide vineyard area and grape berry production were 7,940,150 ha and 100,186,579 t, respectively (Food and Agriculture Organization, 2016). Grape berries are rich in many nutrients and are very appreciated by consumers. However, during the processes of fruit enlargement and maturation, producers apply pesticides to control pests and diseases, which inevitably affect food safety. Although bagging treatment can effectively reduce pesticide residues on the surface of fruit, it may cause low-light stress. Light is an essential environmental factor for plant growth and development, and thus the appearance and flavor quality of fruit could be affected by bagging treatment. Grape berry organoleptic quality depends largely on both the content and composition of sugars, acids, and anthocyanins, which are all influenced by light.

Sugar accumulation is a key factor determining fruit quality in grape berries. Sucrose metabolism is important for sugar accumulation, as this is the main form of sugar transported in grapevine phloem, and it is rapidly metabolized and converted into other sugars, organic acids, and structural substances at the young fruit stage (Shiraishi, 1993; Davies and Robinson, 1996). Low-light environments may influence the transport and transformation of carbohydrates through the micro-domain environment of fruit, leading to changes in specific sugars (Dokoozlian and Kliewer, 1996; Wang et al., 2009). Tartaric and malic acids typically account for more than $90 \%$ of total organic acids in grape berries (Lamikanra et al., 1995; Esteban et al., 1999): enhancing the flavor and contributing to the mouth-feel of table grape berries.

The color of plant flowers and fruit, which is determined by different pigments, is an important visual 
property. Based on their chemical composition, pigments can be divided into flavonoids, carotenoids, chlorophylls, and betalains. Anthocyanins, which are flavonoid compounds, primarily determine organ color in plants (Grotewold, 2006; Tanaka et al., 2008). The synthesis and metabolic pathway of anthocyanins in plants have been the focus of considerable research activity (Petroni and Tonelli, 2011) and, to date, six anthocyanins have been characterized, namely, pelargonidin, cyanidin, delphinidin, peonidin, malvidin, and petunidin. Anthocyanins can be combined with glucose, galactose, and arabinose to generate single or double anthocyanin elements (Figueiredo et al., 1999; Tanaka et al., 2008). In the past few decades, the biosynthesis of anthocyanins has been characterized in model plants, and it has been determined that the biosynthetic process is catalysed in a stepwise manner by chalcone synthase (CHS): chalcone isomerase (CHI): flavanone-3-hydroxylase (F3H): dihydroflavonol 4reductase (DFR): and anthocyanidin synthase (ANS): which are all under the regulation of several myofibroblastic (MYB) transcription factors (He et al., 2010; Petroni and Tonelli, 2011).

Previous studies have shown that light can increase anthocyanin concentrations, particularly in fruit skin (Feng et al., 2014). Cryptochromes, which respond to light, regulate photomorphogenic development by suppressing constitutive photomorphogenic 1 (COP1) activity (Wang et al., 2001; Yang et al., 2001; Liu et al., 2011). Downstream of the photoreceptors, the RING-finger-type protein COP1 acts as a ubiquitin E3 ligase responsible for targeting several photomorphogenesis-promoting transcription factors, including elongated hypocotyl 5 (HY5) (Osterlund et al., 2000): which is a basic leucine zipper (bZIP) transcription factor that binds directly to the promoters of light-inducible genes, such as anthocyanin structural genes, promoting their expression and photomorphogenic development (Smith et al., 2007; Zhang et al., 2011).

To our knowledge, few studies have investigated the effects of light on the gene expression of sugar and anthocyanin biosynthetic pathways in grape berries. In the present study, we examined sugar and anthocyanins accumulation and the patterns of gene expression in the sugar and anthocyanin biosynthetic pathways of grape berries grown under different bagging treatments. Furthermore, we investigated the roles of genes HYS and COP1 in regulating anthocyanin biosynthesis. Taken together, our results provide insight into the regulatory mechanisms of sugar and anthocyanin biosynthesis under low-light stress.

\section{Materials and Methods}

\section{Plant materials and treatments}

Seven-year-old vines of two red table grape (Vitis vinifera $\times V$. labrusca L.) varieties, 'Shenhua' and 'Shenfeng', were grown in a greenhouse ( $4 \mathrm{~m}$ height): to protect them from rain, in Shanghai, China $\left(30^{\circ} 89 \mathrm{~N}, 121^{\circ} 39 \mathrm{E}\right)$. The grapevines were spaced $1.5 \mathrm{~m}$ within each row, and rows were spaced $3 \mathrm{~m}$ and set with a north-south orientation within the greenhouse. The entire vineyard was managed using the same fertilization, irrigation, pruning, and disease control procedures.

Thirty clusters of similar size fruit per variety were selected for experimental manipulation. Bagging treatments, which were performed at 45 days after anthesis (45 DAA, June $\left.30^{\text {th }}, 2017\right)$, comprised no bag $(N)$ or the use of a white bag $(\mathrm{W})$ or a shading light bag $(\mathrm{S})$. The light permeability of each treatment is shown in Table 1. Grape berry samples were taken at $58 \mathrm{DAA}$ (veraison stage): $72 \mathrm{DAA}$ and 85 DAA (trans-chromic stage): and 91/93 DAA ('Shenhua'/Shengfeng', mature stage). Grape berry maturity was determined based on the change in seed color from green to dark brown. At $85 \mathrm{DAA}$, the white and shading bags were removed (treatments WT and ST, respectively).

The juice of twelve grape berries for each treatment was extracted in a juicer and used to determine total soluble solid content (SSC) contents and titratable acidity (TAA). While SSC was determined using a hand refractometer (Master-M; Atago, Tokyo, Japan) and expressed as ${ }^{\circ}$ Brix values, TAA was measured by titration with $0.1 \mathrm{~N} \mathrm{NaOH}$ and expressed as a percentage ( $\mathrm{g}$ tartaric acid/100 mL juice).

The remaining berries within each treatment were peeled with scalpel and forceps, and the cleaned skin tissues were immediately frozen in liquid nitrogen $\left(\mathrm{N}_{2}\right)$ and stored at $-80{ }^{\circ} \mathrm{C}$ for further analyses.

\section{Determination of fruit color}

Fruit color was determined from fruits at the equatorial part of the grapevine using a hand-held C 410 chroma meter (Konika-Minolta, Tokyo, Japan): the light source of which was set to D65 at an angle of $10^{\circ}$. The Commission Internationale de l'Eclairage (CIE) color indexes $\mathrm{L}^{*}$ (brightness): $\mathrm{a}^{*}$ (red-green color component): and $\mathrm{b}^{*}$ (blueyellow color component) were determined and used for calculating the color index of red grape (CIRG) based on the following equation:

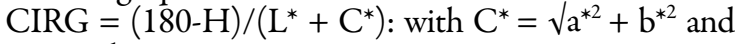
$\mathrm{H}=\arctan \mathrm{b}^{*} / \mathrm{a}^{*}$.

\section{Sugar analysis}

The extraction of soluble sugars was performed according to the methods of $\mathrm{Lu}$ et al. (2011) with minor modifications. Briefly, soluble sugars were extracted from 3 $\mathrm{g}$ of frozen grape berry powder homogenized in $6 \mathrm{~mL}$ ethanol/water $(4: 1 \mathrm{v} / \mathrm{v})$ at $35{ }^{\circ} \mathrm{C}$ for $20 \mathrm{~min}$. The homogenate was centrifuged at $6500 \times g$ for $15 \mathrm{~min}$, and the residues were re-extracted using the same procedure. The supernatants from the two extractions were mixed and brought up to $15 \mathrm{~mL}$ with distilled water. Thereafter, $1 \mathrm{~mL}$ of each extract was evaporated under vacuum at $35^{\circ} \mathrm{C}$, redissolved in $1 \mathrm{~mL}$ MilliQ water (MilliporeSigma, Burlington, MA, USA): and filtered through a $0.45-\mu \mathrm{m}$ Millipore filter. The content of soluble sugars was determined by high-performance liquid chromatography (HPLC) using the Waters E2695 system (Waters, Milford, MA, USA): as described by Ding et al. (2002). The sugar contents were quantified using the following equations obtained from calibration curves: Glucose concentration $(\mathrm{mg} / \mathrm{g})=5 \times 10^{-6} \times$ Area +0.0601 , with $\mathrm{r}^{2}=0.9999 ;$ Fructose concentration $(\mathrm{mg} / \mathrm{g})=5 \times 10^{-6} \times$ Area -0.0615 , with $r^{2}=0.9942$. 
1196

\section{Anthocyanin analysis}

The extraction and measuring of anthocyanins was performed according to $\mathrm{Xi}$ et al. (2016). The HPLC protocol described by Ding et al. (2002) and the E2695 instrument (Waters) equipped with a 2998 photodiode array detector (PAD) were used. Anthocyanins were identified according to their retention time and to the molecular and ion fragment weights of their standards, as well as by comparison to previously published data (Liang et al., 2011, 2012; Xi et al., 2016, 2018). Total anthocyanin content was quantified using cyanidin 3-O-glucoside chloride (Sigma-Aldrich, St. Louis, MO, USA) as a standard and the following equation: concentration $(\mathrm{mg} / \mathrm{g})=8 \times 10^{-}$ ${ }^{5} \times$ Area +4.2211 , with $r^{2}=0.9918$.

\section{Gene expression analyses}

Total RNA was extracted from the skin of grape berries using an E.Z.N.A. Plant RNA Kit (Omega Bio-tek, Doraville, GA, USA). First-strand cDNA was synthesized using a Takara PrimeScript RT reagent Kit with gDNA Eraser (Takara, Dalian, China). Quantitative real-time PCR was performed using the LightCycler 480 System (Roche, Mannheim, Germany) and SYBR Premix Ex Taq II (Tli RNaseH Plus; Takara): according to the methods of $\mathrm{Xi}$ et al. (2016, 2018). Gene transcripts were quantified upon normalization to genes $V v E F I r$ and $V v G A P D H$ (Guillaumie et al., 2013) by using the comparative cycle threshold method $\left(2^{-\Delta c t}\right)$. The normalized expression of genes was calculated using geNorm software (https://genorm.cmgg.be) following a method derived from the algorithms outlined by Vandesompele et al. (2002). All primer sequences were obtained from the literature and are listed in Table S1.

\section{Statistical analysis}

For each sampling period, the data from the three independent replicates of each treatment were expressed as the means \pm standard deviation (SD): and analysed using SPSS v18.0 (SPSS Inc., Chicago, IL, USA).

\section{Results}

Color development of grape berries under different treatments

During the growing period, the color development of grape berries under treatment $\mathrm{N}$ was faster and more extensive than that under treatments $\mathrm{W}$ and $\mathrm{S}$, as expected (Fig. S1 and S2). The bags used in W and S treatments were removed at 85 DAA. The skin color of 'Shenhua' and 'Shenfeng' grapes at maturity are shown in Fig. 1 and 2, respectively. Although the skin color of grape berries in the bagging treatments was less red and black than that in the $\mathrm{N}$ treatment, which tended to become more red and black 6 to 8 days after removing the bags.

A higher value of CIGR indicates a darker skin and, in 'Shenhua' at $91 \mathrm{DAA}$, the CIGR value of the $S$ treatment was the lowest and that of the $\mathrm{N}$ treatment was the highest. However, no significant changes were detected among the CIGR values obtained for 'Shenfeng' grape berries subject to the different treatments at 93 DAA (Table 2).

\section{Quality of grape berries under the different treatments}

The fruit quality data for 'Shenhua' and 'Shenfeng' grape berries at maturity are shown in Table 3. The single fruit weight of 'Shenhua' and 'Shenfeng' grape berries showed no significant differences among the five treatments. In 'Shenhua', the SSC value under the $S$ treatment was the lowest. Although there were no significant differences in SSC values under the WT and W treatments, values under the ST treatment were significantly higher than under the $S$ treatment. In 'Shenfeng,, the SSC value was highest under the $\mathrm{N}$ treatment, although this value differs significantly from that under the other four treatments. Furthermore, there were no significant differences in the TAA of 'Shenhua' grape berries among the five treatments. In 'Shenfeng, the TAA under W and $S$ treatments was significantly higher than that under the other three treatments. The single fruit weights, SSC, and TAA of grape berries during the growth period are shown in Table S2.

Table 1. Light permeability in the different bagging treatments

\begin{tabular}{cccc}
\hline & Photosynthetic active radiation $\left(\mu \mathrm{mol} / \mathrm{m}^{2} / \mathrm{s}\right)$ & \multirow{2}{*}{ Light permeability $(\%)$} \\
\cline { 2 - 3 } & Before bagging & After bagging & 100 \\
No bag & - & - & 24.3 \\
White bag & 1091 & 265 & 0 \\
\hline Shading bag & 1108 & 0 & 0 \\
\hline
\end{tabular}

Table 2. Values of the CIGR index obtained for grape berries skin under the different treatments

\begin{tabular}{|c|c|c|}
\hline \multirow{2}{*}{ Treatment ${ }^{x}$} & \multicolumn{2}{|c|}{ CIGR } \\
\hline & 'Shenhua'(91 DAA) & 'Shenfeng'(93 DAA) \\
\hline $\mathrm{N}$ & $5.09 \pm 0.66 a$ & $5.28 \pm 0.92 a$ \\
\hline W & $4.14 \pm 0.55 b$ & $4.85 \pm 0.77 a$ \\
\hline$S$ & $3.92 \pm 0.47 b$ & $4.62 \pm 0.66 a$ \\
\hline WT & $4.82 \pm 0.54 a b$ & $4.92 \pm 0.87 \mathrm{a}$ \\
\hline ST & $4.76 \pm 0.37 \mathrm{ab}$ & $5.30 \pm 0.50 \mathrm{a}$ \\
\hline
\end{tabular}


A

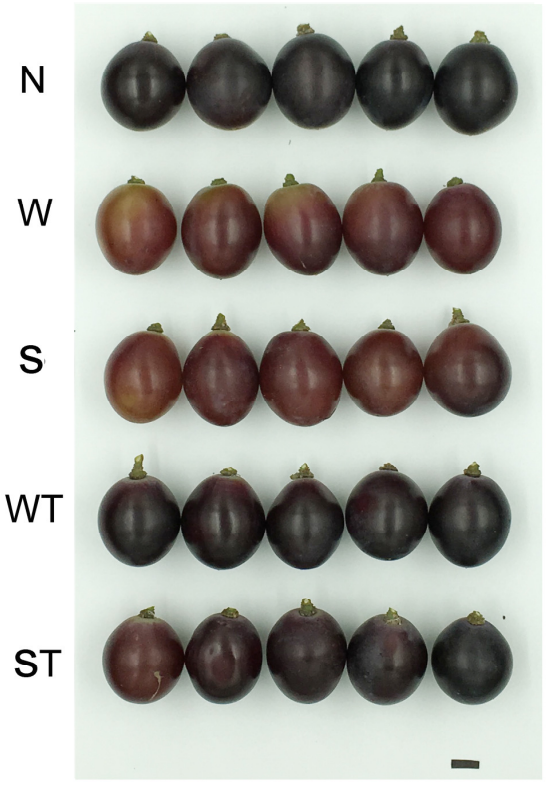

B

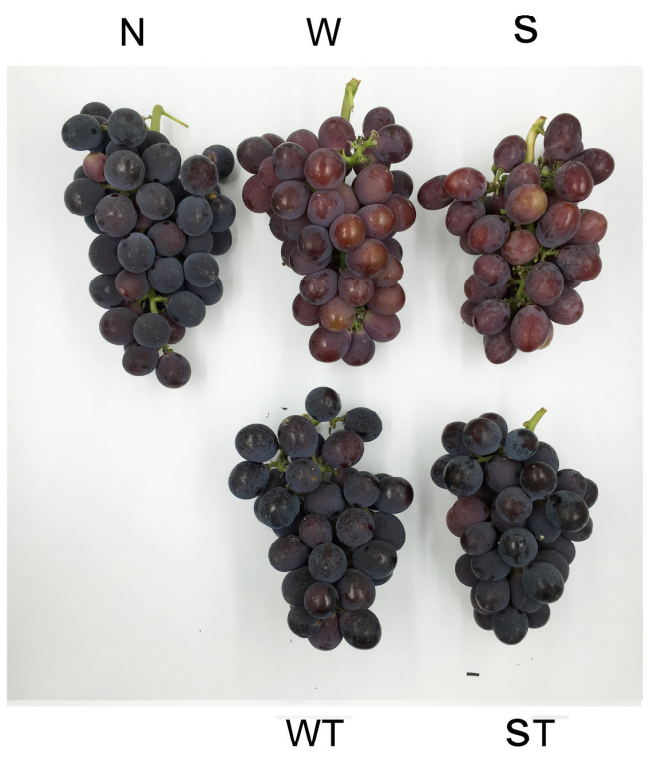

Fig. 1. Grains (A) and spikes (B) of 'Shenhua' grape berries at 91 DAA. N: no bag treatment; W: white bag treatment; S: shading bag treatment; WT: white bag removal treatment; $S$ : shading bag removal treatment $(B a r=1 \mathrm{~cm})$

A

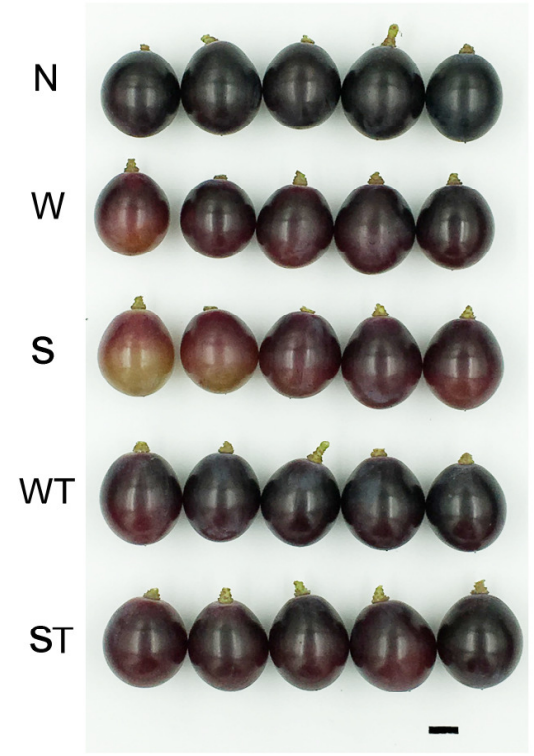

B

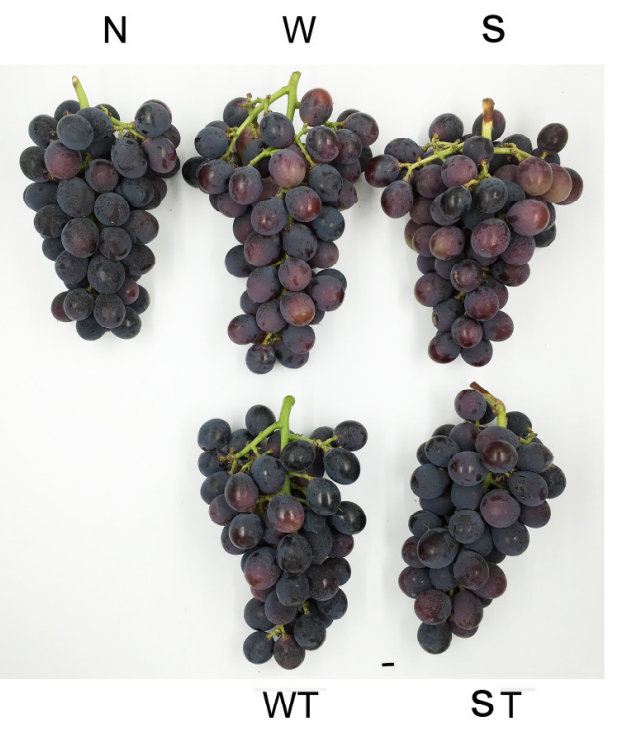

Fig. 2. Grains (A) and spikes (B) of 'Shenfeng' grape berries at 93 DAA. N: no bag treatment; W: white bag treatment; S: shading bag treatment; WT: white bag removal treatment; $S$ : shading bag removal treatment $(B a r=1 \mathrm{~cm})$

For both 'Shenhua' and 'Shenfeng' grape berries, there were no significant differences in single fruit weight among the different treatments from 58 DAA to 85 DAA. However, the SSC of grape berries from both varieties was significantly higher under treatment $\mathrm{N}$ from $58 \mathrm{DAA}$ to 85 DAA than under the other treatments. Notably, in grape berries of both varieties, the TAA of the fruits subject to bagging treatments was sometimes higher than that of fruits under the $\mathrm{N}$ treatment.
The sugar and anthocyanins of grape berries under different treatments

Fructose, glucose, and anthocyanin contents measured in grape berries subject to the N,W, S, WT, and ST treatments are displayed in Fig. 3A, B, D, and E. No significant changes were detected in the sugar (fructose and glucose) contents of both 'Shenhua' and 'Shenfeng' grape berries among the different treatments from 58 DAA to 72 DAA. However, the sugar contents of grape berries under 
1198

the $N$ treatment were higher than those of grape berries under the W and $S$ treatments at 85 DAA. In 'Shenhua' at 91 DAA, sugar contents were significantly higher in grape berries under the WT treatment than in grape berries under the W, S, and ST treatments, whereas in 'Shenfeng' at 93 DAA, the sugar contents of grape berries under treatments $\mathrm{W}$ and $\mathrm{S}$ were significantly lower than those of grape berries under the $\mathrm{N}$ treatment. Although the anthocyanin contents of 'Shenhua' and 'Shenfeng' grape berries showed no changes at $58 \mathrm{DAA}$, which of grape berries under treatment $\mathrm{N}$ was significantly higher than that of grape berries under treatments W and $S$ from 72 DAA to 91/93 DAA. Furthermore, we found that the anthocyanin contents under treatments WT and ST where higher than that under the $\mathrm{W}$ and $S$ treatments, respectively. In both 'Shenhua' and 'Shenfeng' cultivars, the anthocyanin concentrations in grape berry skin throughout the ripening period were considerably lower under bagging treatments than under the $\mathrm{N}$ treatment (Fig. 3C,F). In 'Shenhua' grape berry skin, the amount of anthocyanin at maturity was higher under treatment $\mathrm{N}[4 \mathrm{mg} / \mathrm{g}$ fresh weight $(\mathrm{FW})]$ than under treatments W $(1.2 \mathrm{mg} / \mathrm{g} \mathrm{FW})$ and $S(0.4 \mathrm{mg} / \mathrm{g} \mathrm{FW})$. The amounts of anthocyanin under treatments WT (3.0 $\mathrm{mg} / \mathrm{g} \mathrm{FW})$ and ST (1.6 mg/g FW) were higher than under treatments $W$ and $S$, respectively.
The amounts of cyanidin, delphinidin, malvidin, peonidin, and petunidin derivatives were significantly higher under treatment $\mathrm{N}$ than under the other four treatments. Similarly, the amounts of these five anthocyanin derivatives under treatments WT and ST were higher than those under treatments W and S, respectively (Fig. 4A). At maturity, the amount of anthocyanin in 'Shenfeng' grape berries under treatment $\mathrm{N}(10 \mathrm{mg} / \mathrm{g} \mathrm{FW})$ was higher than that under treatments W $(3.5 \mathrm{mg} / \mathrm{g} \mathrm{FW})$ and $S(1.4 \mathrm{mg} / \mathrm{g}$ FW). In addition, the amounts of anthocyanin under treatments WT $(4.4 \mathrm{mg} / \mathrm{g} \mathrm{FW})$ and ST $(4.5 \mathrm{mg} / \mathrm{g} \mathrm{FW})$ were higher than those under treatments $\mathrm{W}$ and $\mathrm{S}$, respectively. Moreover, the amounts of cyanidin, delphinidin, malvidin, and peonidin derivatives under treatment $\mathrm{N}$ were significantly higher than those under the other four treatments, and the amounts of the derivatives of these four anthocyanins were higher under treatment ST than those under treatment $S$ (Fig. 4B). In 'Shenhua' grape berries at $91 \mathrm{DAA}$, the percentages of cyanidin, petunidin, and peonidin under treatments $\mathrm{W}$ and $\mathrm{S}$ were higher than those under treatment $\mathrm{N}$, but the percentages of delphinidin and malvidin under treatments $\mathrm{W}$ and $\mathrm{S}$ were lower than those under treatment $\mathrm{N}$ (Table 4). In 'Shenfeng' grape berries at $93 \mathrm{DAA}$, the percentages of malvidin and peonidin under treatments $\mathrm{W}$ and $S$ were higher than those under treatment $\mathrm{N}$, but the percentages of cyaniding, delphinidin, and petunidin under treatments $\mathrm{W}$ and $\mathrm{S}$ were higher than those under treatment $\mathrm{N}$.

Table 3. Quality of grape berries under the different treatments at 91/93 DAA

\begin{tabular}{|c|c|c|c|c|}
\hline Variety & Treatment $^{x}$ & Single fruit weight $(\mathrm{g})$ & SSC (\%) & TAA (\%) \\
\hline \multirow{5}{*}{$\begin{array}{l}\text { 'Shenhua' } \\
\text { (91 DAA) }\end{array}$} & $\mathrm{N}$ & $13.60 \pm 0.69 a$ & $17.53 \pm 0.06 \mathrm{a}$ & $1.35 \pm 0.04 \mathrm{a}$ \\
\hline & W & $13.93 \pm 0.50 \mathrm{a}$ & $16.10 \pm 0.10 b c$ & $1.33 \pm 0.11 \mathrm{a}$ \\
\hline & S & $13.60 \pm 0.53 a$ & $15.83 \pm 0.06 c$ & $1.43 \pm 0.10 \mathrm{a}$ \\
\hline & WT & $13.87 \pm 0.42 a$ & $16.67 \pm 0.06 b$ & $1.36 \pm 0.10 \mathrm{a}$ \\
\hline & ST & $13.53 \pm 0.64 a$ & $16.23 \pm 0.38 b$ & $1.50 \pm 0.04 \mathrm{a}$ \\
\hline \multirow{5}{*}{$\begin{array}{l}\text { 'Shenfeng' } \\
\text { (93 DAA) }\end{array}$} & $\mathrm{N}$ & $10.73 \pm 0.81 \mathrm{a}$ & $19.63 \pm 0.06 a$ & $1.25 \pm 0.06 b$ \\
\hline & W & $12.07 \pm 0.12 \mathrm{a}$ & $16.50 \pm 0.10 b$ & $1.40 \pm 0.04 a$ \\
\hline & $S$ & $11.33 \pm 0.50 \mathrm{a}$ & $16.93 \pm 0.32 b$ & $1.38 \pm 0.02 \mathrm{a}$ \\
\hline & WT & $12.20 \pm 0.20 \mathrm{a}$ & $16.90 \pm 0.30 b$ & $1.30 \pm 0.04 b$ \\
\hline & ST & $11.33 \pm 0.81 \mathrm{a}$ & $17.10 \pm 0.10 b$ & $1.28 \pm 0.08 b$ \\
\hline
\end{tabular}

${ }^{\bar{N}} \mathrm{~N}$ : no bag treatment; W: white bag treatment; S: shading bag treatment; WT: white bag removal treatment; ST: shading bag removal treatment

Different lower case letters indicate significant differences $(p<0.05)$

Table 4. Percentages of the five anthocyanin derivatives in grape berries under the different treatments at 91/93 DAA

\begin{tabular}{|c|c|c|c|c|c|c|}
\hline \multirow{2}{*}{ Variety } & \multirow{2}{*}{ Derivative $^{x}$} & \multicolumn{5}{|c|}{ Treatment ${ }^{y}$} \\
\hline & & $\mathrm{N}$ & W & $S$ & WT & ST \\
\hline \multirow{5}{*}{$\begin{array}{l}\text { 'Shenhua' } \\
\text { (91 DAA) }\end{array}$} & $\mathrm{CY}$ & 14.15 & 11.51 & 9.45 & 11.69 & 11.29 \\
\hline & $\mathrm{DP}$ & 7.845 & 7.71 & 7.35 & 5.95 & 7.26 \\
\hline & MV & 64.02 & 63.87 & 61.86 & 69.75 & 66.53 \\
\hline & PN & 9.83 & 10.14 & 12.38 & 8.06 & 8.77 \\
\hline & PT & 4.16 & 6.76 & 8.98 & 4.55 & 6.21 \\
\hline \multirow{5}{*}{$\begin{array}{l}\text { 'Shenfeng' } \\
\text { (93 DAA) }\end{array}$} & $\mathrm{CY}$ & 15.13 & 12.37 & 9.03 & 12.33 & 14.24 \\
\hline & DP & 6.89 & 5.24 & 3.60 & 4.22 & 6.34 \\
\hline & MV & 72.83 & 76.79 & 82.79 & 80.05 & 74.43 \\
\hline & PN & 4.91 & 5.60 & 4.58 & 3.40 & 5.00 \\
\hline & PT & 0.24 & 0 & 0 & 0 & 0 \\
\hline
\end{tabular}

${ }^{x}$ CY: cyanidin derivatives; DP: delphinidin derivatives; MV: malvidin derivatives; PN: peonidin derivatives; PT: petunidin derivatives.

${ }^{y} \mathrm{~N}$ : no bag treatment; W: white bag treatment; S: shading bag treatment; WT: white bag removal treatment; ST: shading bag removal treatment. 

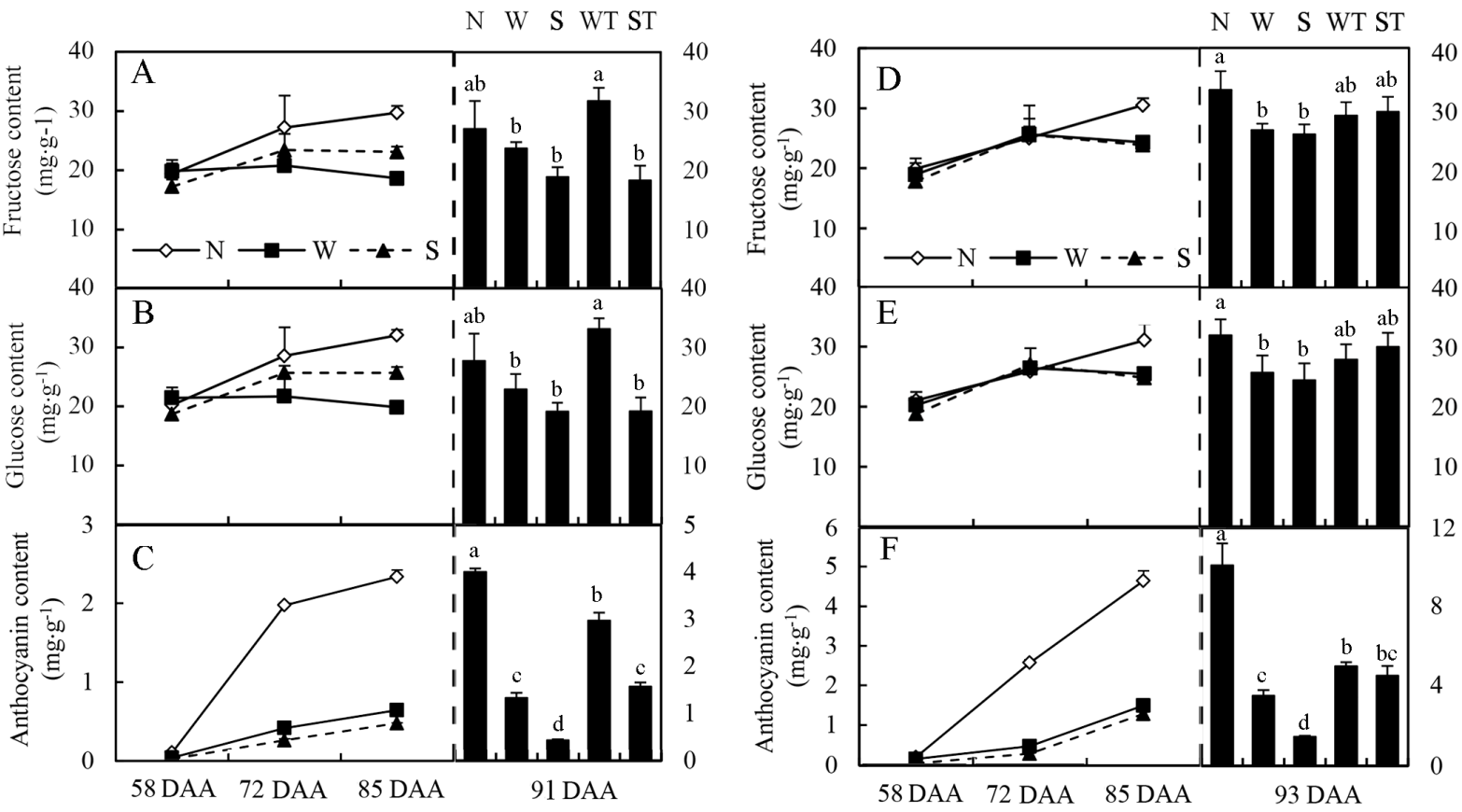

Fig. 3. Fructose, glucose, and anthocyanin contents of 'Shenhua' (A, B, C, respectively) and 'Shenfeng' (D, E, F, respectively) grape berries under the different treatments. N: no bag treatment; W: white bag treatment; S: shading bag treatment; WT: white bag removal treatment; $S$ : shading bag removal treatment. Data are means $\pm S D$ of three biological replicates. Different letters denote a statistically significant difference at $p<0.05$

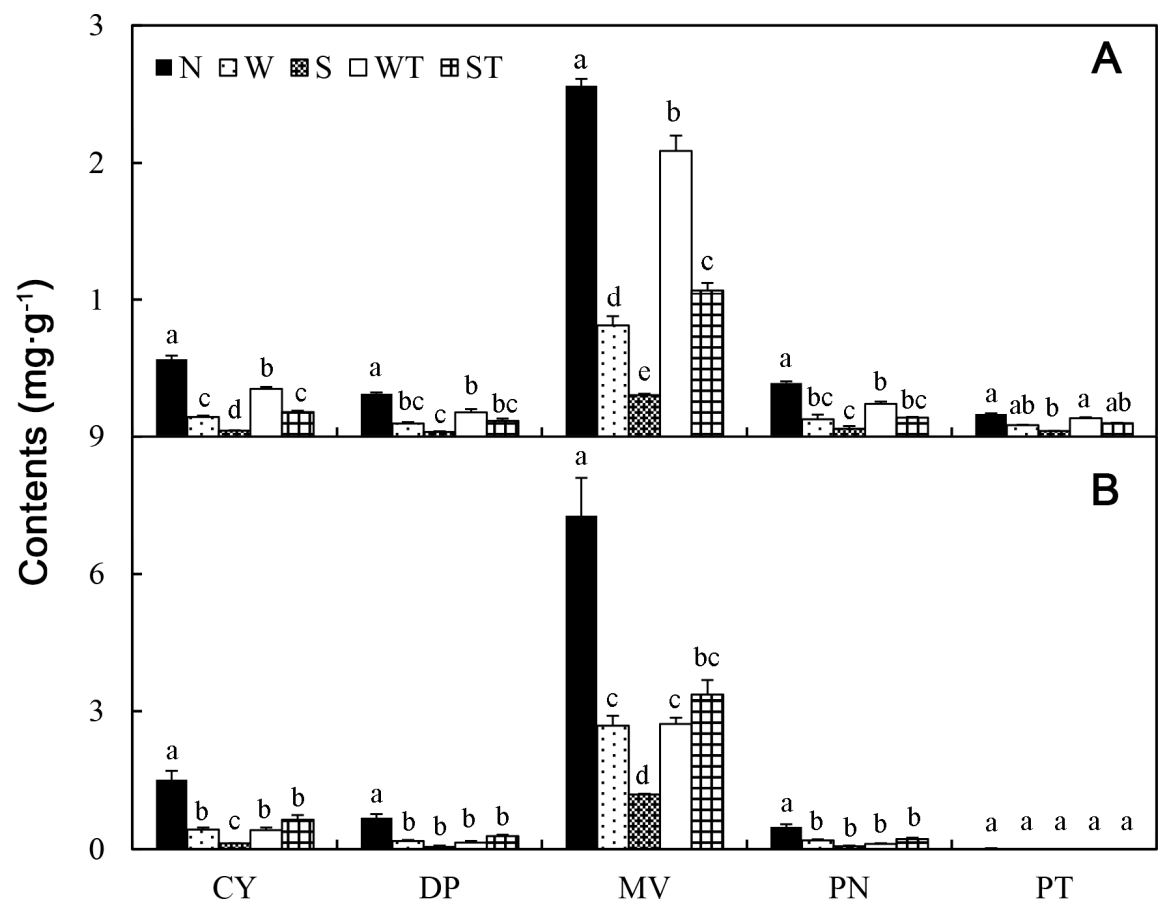

Fig. 4. The contents of the five anthocyanin derivatives in 'Shenhua' (A) and 'Shenfeng' (B) grape berries at 91 DAA and 93 DAA, respectively, under the different treatments in grapevine. CY: cyanidin derivatives; DP: delphinidin derivatives; MV: malvidin derivatives; PN: peonidin derivatives; PT: petunidin derivatives. N: no bag treatment; W: white bag treatment; S: shading bag treatment; WT: white bag removal treatment; ST: shading bag removal treatment. Data are means \pm SD of three biological replicates. Different letters denote a statistically significant difference in anthocyanin derivative contents at $p<0.05$. 
1200

The gene expression of grape berries under different treatments

During the growth period, we detected changes in selected sugar metabolism-related genes in grape berry skin $(V v A I N 1 / 2, V v N I, V v S P S$, and $V v S S)$ among the different treatments (Fig. 5). In 'Shenhua', the expression of $V v A I N 1 / 2$ under treatment $S$ was higher than that under the other treatments from 58 DAA to 72 DAA. Similarly, in 'Shenfeng', the expression of VvAIN2 under treatment $S$ was higher than that under the other treatments from 58 DAA to 93 DAA. In 'Shenhua', at 85 DAA, the expression of $V v N I$ under treatment $\mathrm{N}$ was significantly higher than that under the other treatments, whereas in 'Shenhua', at 93 DAA, the expression of $V v N I$ under treatment $\mathrm{N}$ was significantly higher than that under the other treatments. In 'Shenhua', at $91 \mathrm{DAA}$, the expressions of $V v S P S$ and $V v S S$ under treatments N, WT, and ST was higher than those under treatments W and S, whereas in 'Shenfeng', at 93 DAA, the expression of the same two genes was lower under treatment $S$ than under the other treatments.

In 'Shenhua', at $58 \mathrm{DAA}$, the expressions of VvFLS4 and $V v M Y B F 1$ under treatment $\mathrm{N}$ were significantly higher than those under treatments W and S (Fig. 6). The expressions of $V v C H S 3, V v C H I 1, V v C H I 2, V v M Y B P A 1$, and $V v M Y B 5 a$ under treatment $\mathrm{N}$ were significantly higher than those under treatments $\mathrm{W}$ and $S$ at $72 \mathrm{DAA}$, whereas the expression of $V v M Y B P A 1$ under treatment $\mathrm{N}$ was

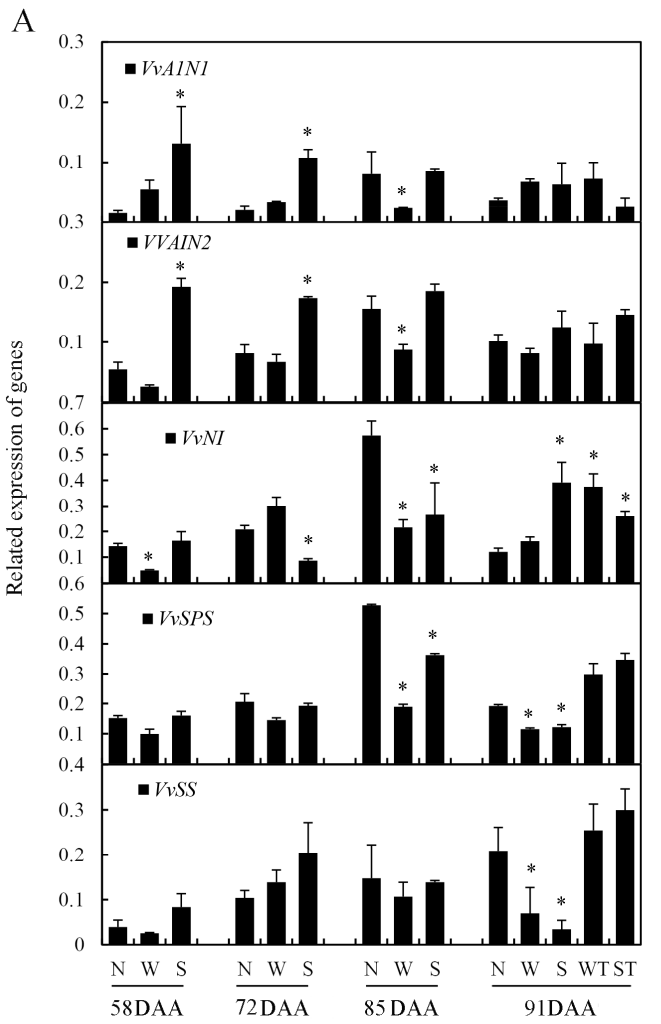

significantly higher than that under the other treatments at 85 DAA. The expressions of $V v C H S 2, V v F 3 H 1, V v D F R$, $V v G S T$, and $V v M Y B F 1$ under treatment $\mathrm{N}$ were higher than those under the other treatments at 91 DAA.

In 'Shenfeng', the expressions of $V v C H S 2, V v C H S 3$, VvCHI2, VvF3'5'H, VvF3H1, VvF3H2, VvMATE, VvDFR, VvOMT, VvFLS4, VvMYBPA1, VvMYBA1, $V v M Y B F 1, V v M Y B 4$, and $V v M Y B 5 b$ under treatment $\mathrm{N}$ were significantly higher than those under treatments W and $S$ at 58 DAA (Fig. 7). The expressions of $V v F 3 H 2$, $V v M A T E, V v G S T, V v F L S 4, V v M Y B F 1, V v M Y B 5 a$, and $V v M Y B 5 b$ under treatment $\mathrm{N}$ were significantly higher than those under treatments $\mathrm{W}$ and $S$ at 72 DAA. The expressions of $V v C H S 2, V v F 3^{\prime} 5^{\prime} H, V v F 3 H 1, V v F 3 H 2$, $V v G S T, V v U F G T, V v F L S 4, V v M B Y P A 1$, and $V v M Y B 5 b$ under treatment $\mathrm{N}$ were significantly higher than those under the other treatments at $85 \mathrm{DAA}$. The expressions of $V v C H S 2, V v F 3 H 1, V v D F R$, and $V v F L S 4$ under treatments $\mathrm{N}, \mathrm{WT}$, and ST were higher than those under treatments $\mathrm{W}$ and $S$ at 93 DAA.

The expression of $V v H Y 5$ was lower under bagging treatments from 58 DAA-85 DAA in 'Shenhua' and from 58 DAA-72 DAA in 'Shenfeng' than under the $\mathrm{N}$ treatment, which was opposite to the expression pattern of $C O P 1$. The expressions of $V v H Y 5$ and $V v C O P 1$ also showed opposite trends in 'Shenhua' and 'Shenfeng' at 91/93 DAA (Fig. 8).

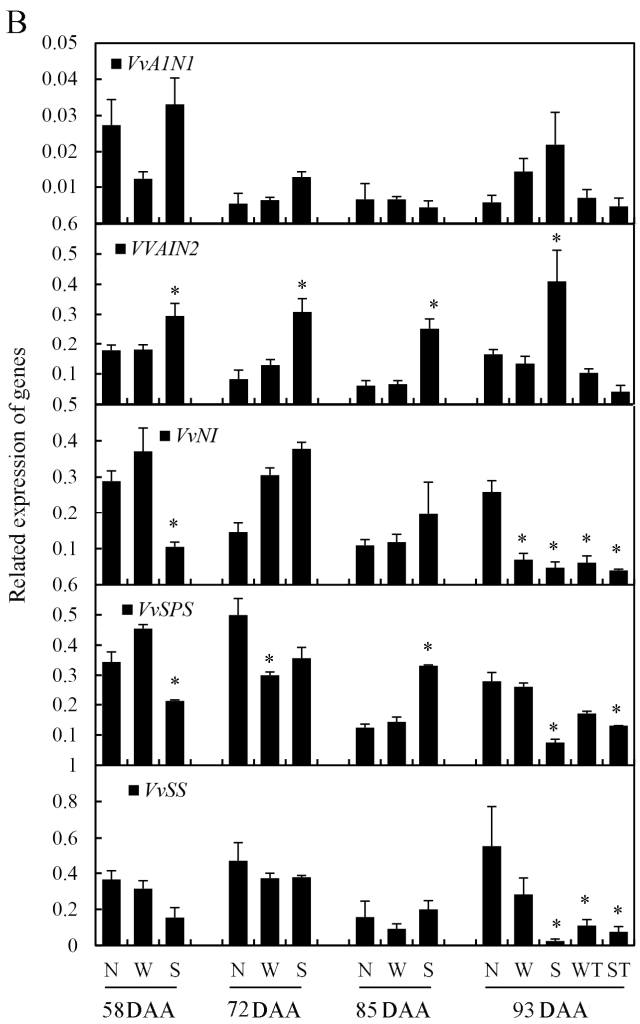

Fig. 5. Expression profiles of sugar metabolism-related genes in 'Shenhua' (A) and 'Shenfeng' (B) grape berries under the different treatments. N: no baag treatment; W: white bag treatment; S: shading bag treatment; WT: white bag removal treatment; S: shading bag removal treatment. Data are means \pm SD of three biological replicates. Asterisks $\left({ }^{*}\right)$ denote a statistically significant difference at $p<0.05$ between bagged/bag-removed treatments and treatment $\mathrm{N}$ 

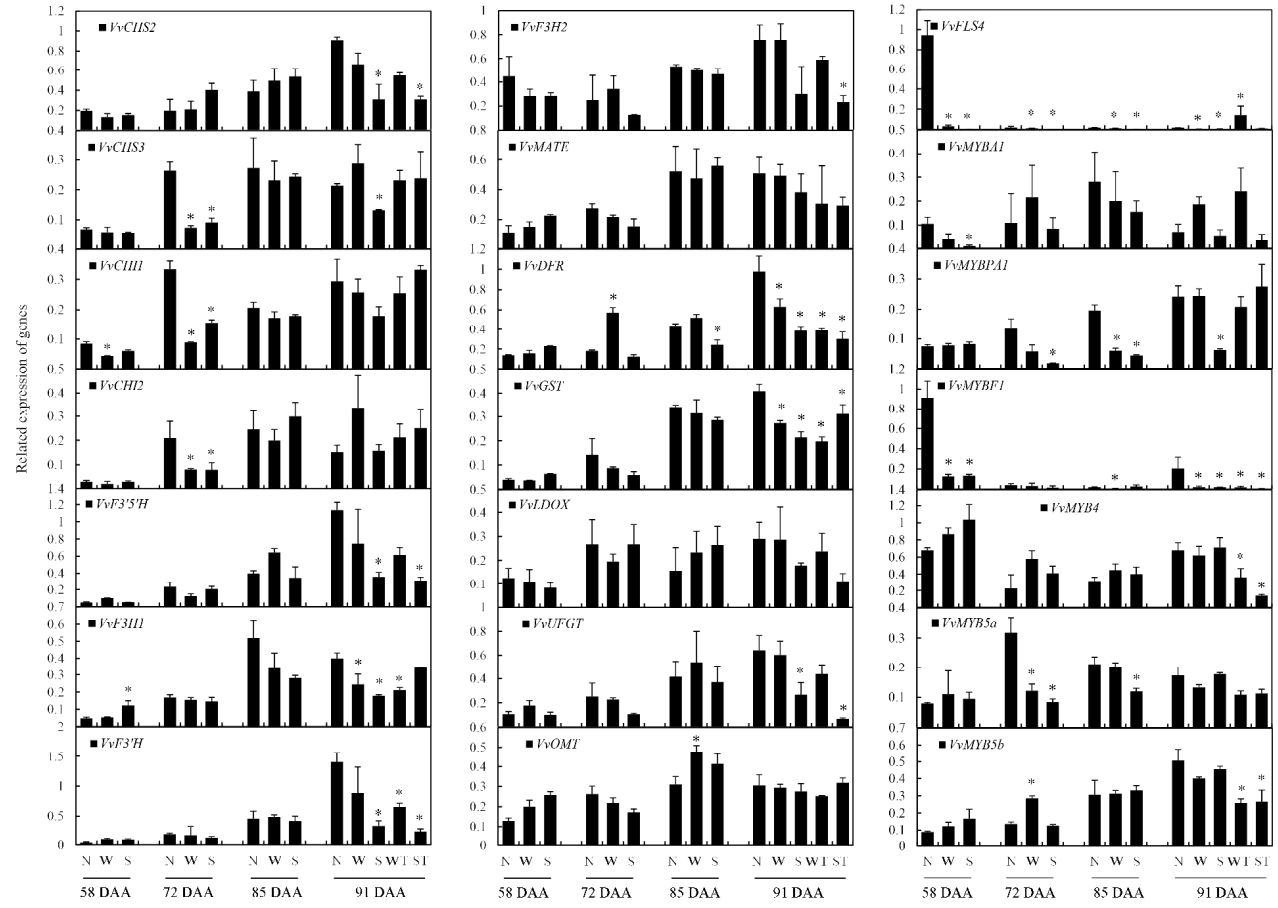

Fig. 6. Expression profiles of anthocyanin metabolism-related genes in 'Shenhua' grape berries under the different treatments. N: no bag treatment; W: white bag treatment; S: shading bag treatment. WT: white bag removal treatment; S: shading bag removal treatment. Data are means \pm SD of three biological replicates. Asterisks $\left(^{*}\right)$ denote a statistically significant difference at $p<0.05$ between bagged/bag-removed treatments and treatment $\mathrm{N}$
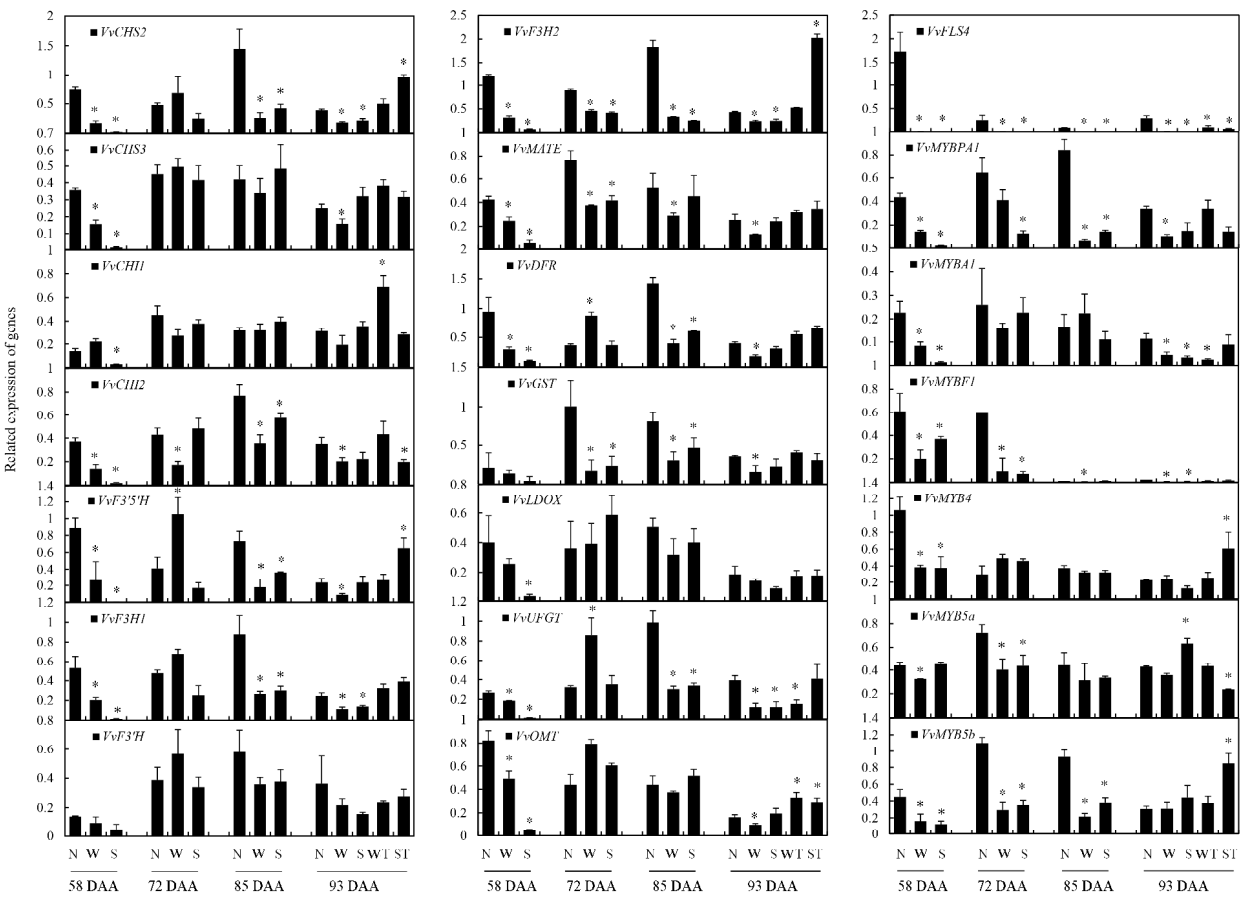

Fig. 7. Expression profiles of anthocyanin metabolism-related genes in 'Shenfeng' grape berries under the different treatments. N: no bag treatment; W: white bag treatment; S: shading bag treatment; WT: white bag removal treatment; S: shading bag removal treatment. Data are means \pm SD of three biological replicates. Asterisks $\left({ }^{*}\right)$ denote a statistically significant difference at $p<0.05$ between bagged/bag-removed treatments and treatment $\mathrm{N}$ 

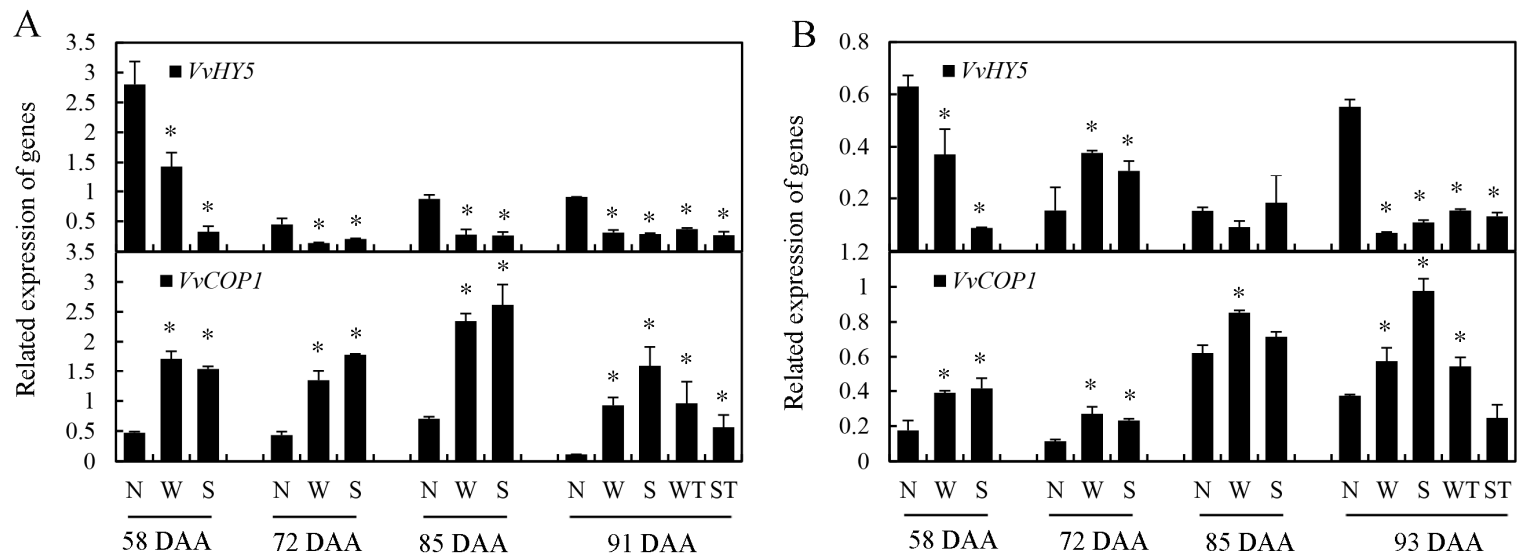

Fig. 8. Expression profiles of HYS and COPI genes in 'Shenhua' (A) and 'Shenfeng' (B) grape berries under the different treatments. N: no bag treatment; W: white bag treatment; S: shading bag treatment. WT: white bag removal treatment; ST: shading bag removal treatment. Asterisks $\left(^{*}\right)$ denote a statistically significant difference at $p<0.05$ between bagged/bag-removed treatments and treatment $\mathrm{N}$

\section{Discussion}

The ripening of 'Shenhua' and 'Shenfeng' grape berries in China occurs mainly in August, which results in a short and specific commercialization time with negative implications for producers. In general, different management practices are used to prolong the grape ripening period, such as early sealing of facilities, treatment with growth regulators, and fruit bagging. Fruit bagging may, however, impose low-light stress on grapevines (Hong et al., 2015). In the present study, we used two types of bags to examine the effects of fruit bagging: one fabricated with material designed to prevent the transmission of all light, and the other consisting of a material that allowed transmission of approximately $30 \%$ of incident light. We found that SSC contents of grape berries were lower under light stress than under normal conditions and that pigment development tended to be delayed under low-light stress conditions. These observations indicated that low light and light exclusion treatments would affect the ripening of grape berries, which is consistent with the findings of previous studies (Keller et al., 1998; Fang et al., 2015; Karanjalker et al., 2018). The maturation of grape berries during the growth stage can thus be delayed by bagging treatments. We also found that delayed ripening is associated with changes in sugar and anthocyanin contents. Thus, we carried out indepth analyses of the contents of sugars and anthocyanins and related gene expression, in order to provide a theoretical basis for explaining the effects of light stress on the ripening of grape berries.

We found that bag removal treatments performed 6 to 8 days before fruit ripening can effectively control fruit ripening, which highlights two scientific considerations. Firstly, fruit ripening is closely related to light, which has similarly been reported in apple and other fruit trees (Smart et al. 1988; Keller et al. 1998; Merzlyak and Chivkunova, 2000). Secondly, cultivation measures such as bagging and bag removal can, to a certain extent, enable producers to control the ripening period of grapes, determine the period when grapes are sold, and improve fruit quality (Sharma et al., 2014a, 2014b, 2018).

The accumulation of sucrose in grape berries is mainly dependent on leaf metabolism, phloem transport, and berry metabolism (Coombe, 1992; Lecourieux et al., 2013). Sucrose can be broken down into glucose and fructose by acidic invertase (AI) and neutral invertase (NI): and into guanosine diphosphate glucose. Fructose in turn can be catalyzed by sucrose synthase (SS): and guanosine diphosphate glucose and fructose-6-phosphate are catalyzed by sucrose phosphate synthase (SPS) to generate sucrose-6phosphate. Thus, glucose and fructose are the main sugar components in grape berries (Coombe, 1989; Liu et al., 2006). In the present study, we found that the accumulation of glucose and fructose during the pre-growth stages of 'Shenhua' and 'Shenfeng' grape berries was not significantly different among the different experimental treatments. During the maturation period, sugar accumulation in 'Shenhua' grape berries was still not significantly related to light stress treatment, whereas bagging treatments significantly affected the accumulation of glucose and fructose in 'Shenfeng' grape berries. The different responses of these two varieties can be related to their specific characteristics.

Under the light-exclusion treatment, expression of the AIN1/2 genes in 'Shenhua' and 'Shenfeng' grape berries was relatively high at some time points, which indicated that the fruit increased sugar storage by increasing enzyme activity. The skin of green grape berries contains photosynthetic products to support the fruit's own growth and development (Yen and Koch, 1990). However, the expression of $N I$ and SPS at $85 \mathrm{DAA}$ and the expression of $S P S$ and $S S$ at 91 DAA in 'Shenhua' indicated that the expression of sugar metabolism-related genes is not directly related to light stress.

In this study, we used two types of bags with different degrees of light transmission. We found that grape berries from both varieties developed color regardless of whether they were exposed to weak light or no light at all, contrasting 
with previous observations on eggplants (Jiang et al., 2016): which are entirely dependent on light reception for the development of fruit color. Zheng et al. (2013) studied two red Chinese Vitis vinifera grape cultivars, namely 'Jingxiu' and 'Jingyan', and found that these were sunlight-dependent and sunlight-independent, respectively. Light exclusion suppresses anthocyanins in the skin of 'Jingxiu' grape berries, but does not change the proportion of the various anthocyanins in the skin of 'Jingyan' grape berries. Based on the results of the present study, we hypothesize that 'Shenhua' and 'Shenfeng' are sunlight-independent varieties that can accumulate sufficient anthocyanins to produce red skin coloration even in the absence of light. However, we observed inconsistencies in the expression of structural genes in the anthocyanin biosynthesis pathway of these two cultivars under the different treatments. This indicates that the expression of structural genes might be light independent, which would be consistent with the findings of Zheng et al. (2013). In addition, the expressions of $V v C H S 2, V v F 3 H 1$, and $V v D F R$ at 91/93 DAA were higher under treatment $\mathrm{N}$ than under treatments W, S, WT, and ST, although no significant differences were detected between the W/S and WT/ST treatments. In several other fruits, including apple and pear, it has been demonstrated that structural genes involved in anthocyanin biosynthesis are not expressed in darkness, but their expression can be enhanced by sunlight (Kim et al., 2003; Zhang et al., 2011; Zheng et al., 2013).

There are five major types of anthocyanin derivatives in grape berry skin (Xi et al., 2016, 2018): and the data obtained here (Table 4) revealed that anthocyanin derivatives composition varied greatly among the grape berries from the two varieties. These derivatives may be positively correlated with light in one variety, but be negatively correlated with light in another. Thus, the relationships between light and individual anthocyanin derivatives were worthy of further analyses.

The expressions of the regulatory genes $V v M Y B F 1$, $V v M Y B 5 a$, and $V v M Y B P A 1$ at $58 \mathrm{DAA}, 72 \mathrm{DAA}$, and 85 $\mathrm{DAA}$, respectively, were higher under treatment $\mathrm{N}$ than under the other treatments. Thus, before the maturation period, the expression of these genes might be light related. In this regard, we examined the relationship among light, anthocyanin biosynthesis, and the transcript levels of $M Y B$ genes. It has been shown that $M Y B$ genes determine the light-induced phenotype of petunia (Albert et al., 2009): whereas in maize, these genes play an important role in the regulation of anthocyanin biosynthesis in response to different light qualities (Procissi et al., 1997; Piazza et al., 2002) and sunlight (Takos et al., 2006; Feng et al., 2014). These responses probably involve light-responsive genes, such as HYS and COP1, and the flavonoid biosynthesis pathway. $H Y 5$ and $C O P 1$ are downstream signal elements of photoreceptors and are widely involved in photomorphogenesis and in the regulation of anthocyanin synthesis (Ang et al., 1998; Chattopadhyay et al., 1998). Under light conditions, HY5 can activate the expression of genes related to the anthocyanin synthesis pathway, particularly $C H S, D F R$, and leucoanthocyanidin dioxygenase $(L D O X)$ (Schulze-lefert et al., 1989; Gollop et al., 2001, 2002). Conversely, under dark conditions, $V v C O P 1$ can ubiquitinate and degrade the HY5 protein, thereby inhibiting the synthesis of anthocyanins (Lau and Deng, 2012).In the present study, the expressions of $V v H Y 5$ and $V v C O P 1$ showed opposite patterns, being higher and lower under the $\mathrm{N}$ treatment than under the other treatments, respectively. Accordingly, $V v H Y 5$ seems to be a light-responsive factor that plays a positive role in the accumulation of anthocyanins in grape berry skin, whereas $V v C O P 1$ has the opposite effect.

\section{Conclusions}

Bagging significantly affects the metabolism of sugars and anthocyanins in 'Shenhua' and 'Shenfeng' grape berries. Bagged berries contained lower contents of soluble sugars than un-bagged berries; however, the reduced contents could be rapidly restored to normal levels following bag removal. The skin of bagging grape berries were poorly colored and had lower contents of anthocyanins than that of un-bagging grape berries. Furthermore, anthocyanin anabolism was affected by the expression of $V v M Y B$ genes and by the light-response factors $V v H Y 5$ and $V v C O P 1$.

\section{Acknowledgements}

This research was partially funded by the Shanghai Sailing Program [grant number 19YF1443300], and the Modern Agricultural Industry Technology System (Grape) [grant number CARS-29-10].

\section{Conflict of Interest}

The authors declare that there are no conflicts of interest related to this article.

\section{References}

Albert NW, Lewis DH, Zhang H, Irving LJ, Jameson PE, Davies KM (2009). Light-induced vegetative anthocyanin pigmentation in petunia. Journal of Experimental Botany 60(7):2191-2202.

Ang LH, Chattopadhyay S, Wei N, Oyama T, Okada K, Batschauer A, Deng XW (1998). Molecular interaction between COPland HY5 defines a regulatory switch for light control of Arabidopsis development. Molecular Cell 1(2):213-222.

Azuma A, Kobayashi S, Goto-Yamamoto N, Shiraishi M, Mitani N, Yakushiji H, Koshita Y (2009). Color recovery in berries of grape (Vitis vinifera L.) 'Benitaka', a bud sport of 'Italia', is caused by a novel allele at the VvmybA1 locus. Plant Science 176(4):470-478.

Chattopadhyay S, Ang LH, Puente P, Deng XW, Wei N (1998). Arabidopsis bZIP protein HY5 directly interacts with light-responsive promoters in mediating light control of gene expression. Plant Cell 10(5):673-683.

Coombe BG(1989). The grape berry as a sink. Acta Horticulturae 239:149158.

Coombe BG (1992). Research on development and ripening of the grape berry. American Journal of Enology and Viticulture 43(1):101-110. 
1204

Cutanda-Perez MC, Ageorges A, Gomez C, Vialet S, Terrier N, Romieu C (2009). Ectopic expression of VlmybAl in grapevine activates a narrow set of genes involved in anthocyanin synthesis and transport. Plant Molecular Biology 69(6):633-648.

Davies C, Robinson SP (1996). Sugar accumulation in grape berries (cloning of two putative vacuolar invertase cDNAs and their expression in grapevine tissues). Plant Physiology 111(1):275-283.

Deluc L, Bogs J, Walker AR, Ferrier T, Decendit A, Merillon JM, ... Barrieu F (2008). The transcription factor VvMYB5b contributes to the regulation of anthocyanin and proanthocyanidin biosynthesis in developinggrape berries. Plant Physiology 147(4):2041-2053.

Ding CK, Chachin K, Ueda Y, Imahori Y, Wang CY (2002). Modified atmosphere packaging maintains postharvest quality of loquat fruit. Postharvest Biology Technology24(3):341-348.

Dokoozlian NK, Kliewer WM (1996). Influence of light on grape berry growth and composition varies during fruit development. Journal of American Society Horticulture Science 121(5):869-874.

Esteban A, Alia I, Tobin M J, Gil A, Gordo F, Vallverdú I, ... Torres A (1999). Effect of spontaneous breathing trial duration on outcome of attempts to discontinue mechanical ventilation. American Journal of Respiratory and Critical Care Medicine 159(2):512-518.

Fang HH, Chiou KD, Liang YS (2015). Bagging management and breeding strategy for red sugar apple (Annona squamosa L.). International Symposium on GA3 Tropical Fruit (Guava, Wax Apple, Pineapple and Sugar Apple) 1166:203-208.

FAO (2016).FAO. Retrieved 2018 March 21 from http://faostat.fao.org

Feng F, Li M, Ma F, ChengL (2014). The effects of bagging and debagging on external fruit quality, metabolites and the expression of anthocyanin biosynthetic genes in 'Jonagold' apple (Malusdomestica Borkh.). Scientia Horticulturae 165:123-131.

Figueiredo JL, Pereira MFR, Freitas MMA, Órfăo JJM (1999). Modification of the surface chemistry of activated carbons. Carbon 37(9):1379-1389.

Gollop R, Even S, Colovatsolova V, Perl A (2002). Expression of the grape dihydroflavonol reductase gene and analysis of its promoter region. Journal of Experimental Botany 53(373):1397-1409.

Gollop R, Farhi S, Perl A (2001). Regulation of the leucoanthocyanidin dioxygenase gene expression in Vitis vinifera. Plant Science 161(3):579588.

GrotewoldE (2006). The science of flavonoids. Springer, New York pp 239267.

Guillaumie S, Ilg A, Réty S, Brette M, Trossat-Magnin C, Decroocq S, ... Gomès E (2013). Genetic analysis of the biosynthesis of 2-methoxy-3isobutylpyrazine, a major grape-derived aroma compound impacting wine quality. Plant Physiology 162(2):604-615.

He F, Yan G, Liang N , Pan Q, Wang J, Reeve MJ, Duan C (2010). Biosynthesis of anthocyanins and their regulation in colored grapes. Molecules 15(12):9057-9091.

Hong W, Ying W, Shuang XU, Zhu WM(2015). Light quality-controlled phytochemicals biosynthesis in vegetables and fruits. Journal of Agricultural Science and Technology 16(9):2029-2035.

Jeong ST, Goto-Yamamoto N, Kobayashi S, Esaka M (2004). Effects of plant hormones and shading on the accumulation of anthocyanins and the expression of anthocyanin biosynthetic genes in grape berry skins. Plant Science 167(2):247-252.

Jiang M, Ren L, Lian H, Liu Y, Chen H (2016). Novel insight into the mechanism underlying light-controlled anthocyanin accumulation in eggplant (Solanum melongena L.). Plant Science 249:46-58.

Karanjalker GR, Ravishankar KV, Shivashankara KS, Esaka M (2018). Influence of baging on color, anthocyanin and anthocyanin biosynthetic genes in peel of red colored mango cv. 'Lily'. ErwerbsObstbau 60(4):281-287.

Keller M, Arnink KJ, Hrazdina G (1998.) Interaction of nitrogen availability during bloom and light intensity during veraison. I. Effects on grapevine growth, fruit development, and ripening. American Journal of Enology andViticulture 49(3):333-340.

Kim SH, Lee JR, Hong ST, Yoo YK, An G, Kim SR (2003). Molecular cloning and analysis of anthocyanin biosynthesis genes preferentially expressed in apple skin. Plant Science 165(2):403-413.

Lamikanra O, Inyang ID, Leong S (1995). Distribution and effect of grape maturity on organic acid content of red muscadine grapes. Journal of Agriculture and Food Chemistry 43(12):3026-3028.

Lau OS, Deng XW (2012). The photomorphogenic repressors COP1 and DET1: 20 years later. Trends in Plant Science 17(10):584593.

Lecourieux F, Kappel C, Lecourieux D, Serrano A, Torres E, Arce-Johnson P, Delrot $S$ (2013). An update on sugar transport and signalling in grapevine. Journal of Experimental Botany 65(3):821-832.

LiangZC, Owens CL, Zhong GY, ChengLL (2011). Polyphenolic profiles detected in the ripe berries of Vitis vinifera germplasm. Food Chemistry 129(3):940-950.

Liang ZC, Sang M, Wu BH, Ma AH, Zhao SJ, Zhong GY, Li SH (2012) Inheritance of anthocyanin content in the ripe berries of a tetraploid $x$ diploid grape cross population. Euphytica 186(2):343-356.

Liu B, Zuo Z, Liu H, Liu X, Lin C (2011). Arabidopsis cryptochrome 1 interacts with SPA1 to suppress COP1 activity in response to blue light. Genes Development 25(10):1029-1034.

Liu HF, Wu BH, Fan PG, Li SH, Li LS (2006). Sugar and acid concentrations in 98 grape cultivars analyzed by principal component analysis. Journal of Science and Food Agriculture 86(10):1526-1536.

Lu CY, Zheng XY, Jia HJ, Lu RG, Teng YW (2011). Effects of root restriction on soluble sugar contents and related enzyme activities in 'Jumeigui' grape berries. Acta Horticulturae Sinica 38(5):825-832.

Matus J T, Aquea F, Arce-Johnson P (2008). Analysis of the grape MYB R2R3 subfamily reveals expanded wine quality-related clades and conserved gene structure organization across Vitis and Arabidopsis genomes. BMC Plant Biology 8(1):83.

Matus JT, Loyola R, Vega A, Peňa-Neira A, Bordeu E, Arce-Johnson P, Alcalde JA (2009). Post-veraison sunlight exposure induces MYBmediated transcriptional regulation of anthocyanin and flavonol synthesis in berry skins of Vitis vinifera. Journal of Experiment Botany 60(3):853-867.

Merzlyak MN, Chivkunova OB (2000). Light-stress-induced pigment changes and evidence for anthocyanin photoprotection in apples. Journal of Photochemistry and Photobiology B: Biology 55(2-3):155163.

Osterlund MT, Wei N, Deng XW (2000). The roles of photoreceptor 
systems and the COP1-targeted destabilization of HY5 in light control of Arabidopsis seedling development. Plant Physiology 124(4):15201524.

Petroni K, Tonelli C (2011). Recent advances on the regulation of anthocyanin synthesis in reproductive organs. Plant Science 181(3):219229.

Piazza P, Procissi A, Jenkins GI, Tonelli C (2002). Members of the cl/pll regulatory gene family mediate the response of maize aleurone and mesocotyl to different light qualities and cytokines. Plant Physiology 128(3):1077-1086.

Procissi A, Dolfini S, Ronchi A, Tonelli C (1997). Light-dependent spatial and temporal expression of pigment regulatory genes in developing maize seeds. Plant Cell 9(9):1547-1557.

Schulze-lefert P, Becker-andré M, Schulz W, Hahlbrock K, DangIJ (1989). Functional architecture of the light-responsive chalcone synthase promoter from parsley. Plant Cell 1(7):707-714.

Sharma RR, Sanikommu VR (2018). Preharvest fruit bagging for better protection and postharvest quality of horticultural produce. In: Preharvest modulation of postharvest fruit and vegetable quality. Academic Press pp 455-489.

Sharma RR, Reddy SVR, Jhalegar MJ (2014a). Pre-harvest fruit bagging: a useful approach for plant protection and improved post-harvest fruit quality-a review. Journal of Horticultural Science and Biotechnology 89(2):101-113.

Sharma RR, Sagar VR, Kumar K(2014b). Effect of pre-harvest fruit bagging on colour, quality and bitter pit disorder in 'Royal Delicious' apple. NISCAIROnline Periodicals Repository22(1):53-57.

Shin J, ParkE, Choi G (2007).PIF3 regulates anthocyanin biosynthesis in an HY5-dependent manner with both factors directly binding anthocyanin biosynthetic gene promoters in Arabidopsis. Plant Journal 49(6):981-994.

ShiraishiM(1993). Three descriptors for sugars to evaluate grape germplasm. Euphytica 71(1-2):99-106.

Smart RE, Smith SM, Winchester RV (1988) Light quality and quantity effects on fruit ripening for Cabernet Sauvignon. American Journal of Enology and Viticulture 39(3):250-258.

Takos A, Robinson S, Walker A (2006) Transcriptional regulation of the flavonoid pathway in the skin of dark grown Cripps red apples in response to sunlight. Journal of Horticultural Science and Biotechnology 81(4):735-744.

Tanaka Y, Sasaki N, Ohmiya A (2008). Biosynthesis of plant pigments: anthocyanins, betalains and carotenoids. Plant Journal 54 (4):733-749.

Terrier N, Glissant D, Grimplet J, Barrieu F, Abbal P, Couture C, ... Hamdi $S$ (2005). Isogene specific oligo arrays reveal multifaceted changes in gene expression during grape berry (Vitis vinifera L.) development. Planta 222(5):832-847.
Vandesompele J, De Preter K, Pattyn F, Poppe B, Roy NV, Paepe AD, Speleman $F$ (2002). Accurate normalization of real-time quantitative RT-PCR data by geometric averaging of multiple internal control genes. Genome Biology3(7):0034.1.

Wang B, He JJ, Bai Y, Yu XM, LiJF, Zhang CX, ... WangSP (2013) Root restriction affected anthocyanin composition and up-regulated the transcription of their biosynthetic genes during berry development in 'Summer Black' grape. Acta Physiologiae Plantarum 35(7):2205-2217.

Wang H, Ma LG, LiJM, Zhao HY, Deng XW (2001.) Direct interaction of Arabidopsis cryptochromes with COP1 in light control development. Science 294(5540):154-158.

WangSY, Chen CT, Wang CY (2009). The influence of light and maturity on fruit quality and flavonoid content of red raspberries. Food Chemistry 112(3):676-684.

Xi XJ, Zha Q, Jiang A L, Tian YH (2016). Impact of cluster thinning on transcriptional regulation of anthocyanin biosynthesis-related genes in 'Summer Black' grapes. Plant Physiology Biochemistry 104:180-187.

Xi XJ, Zha Q, Jiang A L, Tian YH (2018). Stimulatory effect of bunch thinning on sugar accumulation and anthocyanin biosynthesis in 'Shenhua' grape berry (Vitis vinifera $\times$ V. labrusca). Australian Journal of Grape and Wine Research 24(2):158-165.

Yang HQ, Tang RH, Cashmore AR (2001). The signaling mechanism of Arabidopsis CRY1 involves direct interaction with COP1. Plant Cell 13(12):2573-2587.

Yen C R, Koch KE (1990). Developmental changes in translocation and localization of $14 \mathrm{C}$-labeled assimilates in grapefruit: Light and dark $\mathrm{CO} 2$ fixation by leaves and fruit. Journal of American Society Horticultural Science 115(5):815-819.

Zhang H, He H, Wang X, Wang X, Yang X, Li L (2011). Genome-wide mapping of the HY5-mediated gene networks in Arabidopsis that involve both transcriptional and post-transcriptional regulation. Plant Journal 65(3):346-358.

Zheng Y, Li JH, Xin HP, Wang N, Guan L, Wu BH, Li SH (2013). Anthocyanin profile and gene expression in berry skin of two red Vitis vinifera grape cultivars that are sunlight dependent versus sunlight independent. Australian Journal of Grape and Wine Research 19(2):238-248.

Zhu X, Zhang C, Wu W, Li X, Zhang C, FangJ (2017). Enzyme activities and gene expression of starch metabolism provide insights into grape berry development. Horticulture Research 4:17018. 
Supplementary files

Table S1. Primers used for the quantification of gene expression levels by qRT-PCR

\begin{tabular}{|c|c|c|c|}
\hline Gene name & Primer & Sequence $\left(5^{\prime} \rightarrow 3^{\prime}\right)$ & Reference \\
\hline \multirow{2}{*}{ CHSI } & $\mathrm{F}$ & CAGGCAGACTACCCGGATT & \multirow{2}{*}{ Wang et al., 2013} \\
\hline & $\mathrm{R}$ & ACAGACGTTGGGGTTCTCC & \\
\hline \multirow{2}{*}{ CHS2 } & $\mathrm{F}$ & GAAGATGGGAATGGCTGCTG & \multirow{2}{*}{ Jeong et al., 2004} \\
\hline & $\mathrm{R}$ & AAGGCACAGGGACACAAAAG & \\
\hline \multirow{2}{*}{ CHS3 } & $\mathrm{F}$ & TCGGCTGAGGAAGGGCTGAA & \multirow{2}{*}{ Jeong et al., 2004} \\
\hline & $\mathrm{R}$ & GGCAAGTAAAGTGGAAACAG & \\
\hline \multirow{2}{*}{ CHII } & $\mathrm{F}$ & CAGGCAACTCCATTCTTTTC & \multirow{2}{*}{ Jeong et al., 2004} \\
\hline & $\mathrm{R}$ & ТTСТСТАТСАСТGСАТTССС & \\
\hline \multirow{2}{*}{$F 3 H I$} & $\mathrm{~F}$ & CCAATCATAGCAGACTGTCC & \multirow{2}{*}{ Jeong et al., 2004} \\
\hline & $\mathrm{R}$ & TCAGAGGATACACGGTTGCC & \\
\hline \multirow{2}{*}{$\mathrm{F}_{3} \mathrm{H}_{2}$} & $\mathrm{~F}$ & CTGTGGTGAACTCCGACTGC & \multirow{2}{*}{ Jeong et al., 2004} \\
\hline & $\mathrm{R}$ & CAAATGTTATGGGCTCCTCC & \\
\hline \multirow{2}{*}{$F 3^{\prime} H$} & $\mathrm{~F}$ & GCCTCCGTTGCTGCTCAGTT & \multirow{2}{*}{ Jeong et al., 2006} \\
\hline & $\mathrm{R}$ & GAGAAGAGGTGGACGGAGCAAATC & \\
\hline \multirow{2}{*}{$F^{\prime} \mathrm{S}^{\prime} \mathrm{H}$} & $\mathrm{F}$ & AAACCGCTCAGACCAAAACC & \multirow{2}{*}{ Jeong et al., 2006} \\
\hline & $\mathrm{R}$ & ACTAAGCCACAGGAAACTAA & \\
\hline \multirow{2}{*}{ DFR } & $\mathrm{F}$ & GAAACCTGTAGATGGCAGGA & \multirow{2}{*}{ Jeong et al., 2004} \\
\hline & $\mathrm{R}$ & GGCCAAATCAAACTACCAGA & \\
\hline \multirow{2}{*}{$L D O X$} & $\mathrm{~F}$ & AGGGAAGGGAAAACAAGTAG & 502000 \\
\hline & $\mathrm{R}$ & ACTCTTTGGGGATTGACTGG & Jeong et all, 2004 \\
\hline UIFGT & $\mathrm{F}$ & GGGATGGTAATGGCTGTGG & Jeoneretal 2004 \\
\hline UFUT & $\mathrm{R}$ & ACATGGGTGGAGAGTGAGTT & Jeong et all, 2004 \\
\hline$O M T$ & $\mathrm{~F}$ & GTTCAACTTCATGAGATGGA & Azuma et al 2009 \\
\hline$O M I$ & $\mathrm{R}$ & GGAGAACTACCTCAACTACCA & Azuma et al., 200 ' \\
\hline$C S T$ & $\mathrm{~F}$ & ACTTGGTGAAGGAAGCAGGA & Terrier et al. 2005 \\
\hline$G J I$ & $\mathrm{R}$ & CAGCGAGCTCCATGACTTTT & 1 errier et al., 2003 \\
\hline MATE & $\mathrm{F}$ & GCAAACAACAGAGAGGATGC & Cutanda-Perez et al., 2009 \\
\hline MIATL & $\mathrm{R}$ & AGACCTCGACAATGATCTTAC & \\
\hline & $\mathrm{F}$ & GTGCAGCAGCCATCTAATGTG & Matus et al., 2009 \\
\hline MIBSa & $\mathrm{R}$ & GCAGCAGGTTCCCAGACAGT & Miatus et al, $200 \%$ \\
\hline$M Y B S h$ & $\mathrm{~F}$ & GGTGTTCTTTAATTTGGCTTCA & Deluceral 2008 \\
\hline$M T D S D$ & $\mathrm{R}$ & CACAACAACACAACCACATACA & Defluc et al., 2000 \\
\hline MYBPAI & $\mathrm{F}$ & CATGCACGTGCTCACCTT & Azuma et al 2012 \\
\hline & $\mathrm{R}$ & CCGCACGTATCGCTATTATAAG & Azuma et al., zO1L \\
\hline$M Y B A I$ & $\mathrm{~F}$ & TAGTCACCACTTCAAAAAGG & Jeong et al., 2004 \\
\hline & $\mathrm{R}$ & GAATGTGTTTGGGGTTTATC & \\
\hline MYBA & $\mathrm{F}$ & ACCGGACGTTACAACCATATC & Matusetal 2008 \\
\hline 101107 & $\mathrm{R}$ & TCCGTAACTGGGTTTTTCTCA & Matus et al., 2008 \\
\hline$C O P 1$ & $\mathrm{~F}$ & AGGAGGTTTCAACGGGTGC & This study \\
\hline$C O P 1$ & $\mathrm{R}$ & TAGGGCAGAGCGAGTCTTTATC & inis study \\
\hline$H Y 5$ & $\mathrm{~F}$ & CCGGCTGACAAAGAGAACAA & This study \\
\hline 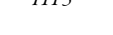 & $\mathrm{R}$ & СТTCCTTTCCCTTGCTTGCT & mis study \\
\hline VvAINI & $\mathrm{F}$ & ССАТСТССАТСССАТСGTAАСС & Zhuet al 2017 \\
\hline & $\mathrm{R}$ & GGCTATCCAAGTTTCCAACCAACC & Zhu et al., 201 ; \\
\hline VvAIN2 & $\mathrm{F}$ & GAGCACAGTTCCAGTAATCAAAGG & Zhu et al., 2017 \\
\hline & $\mathrm{R}$ & GTGAGGCGTAGTTTTAGGACTCC & \\
\hline$V v N I$ & $\mathrm{~F}$ & GGCTTGGGAAGAGGACTATG & Zhu et al., 2017 \\
\hline & $\mathrm{R}$ & GTTGCCTAAACGACGGTAAAT & \\
\hline$V \nu S P S$ & $\mathrm{~F}$ & ACGCTGGGCTGCTTCTAC & Zhu et al., 2017 \\
\hline & $\mathrm{R}$ & AGGGGATCAATTCTGGTTTC & \\
\hline VoSS & $\mathrm{F}$ & CTGGGGTTTATGGGTTCTG & Zhu et al., 2017 \\
\hline & $\mathrm{R}$ & AATGCCTCTGCCTTTTAGC & \\
\hline VvEFIr & $\mathrm{F}$ & CAAGAGAAACCATCCCTAGCTG & Guillaumie et al., 2013 \\
\hline & $\mathrm{R}$ & TCAATCTGTCTAGGAAAGGAAG & \\
\hline$V v G A P D H$ & F & TTCCGTGTTCCTACTGTTG & Guillaumie et al., 2013 \\
\hline
\end{tabular}


Table S2. The fruit quality of grapevine under different treatments

Supplementary files

\begin{tabular}{|c|c|c|c|c|c|}
\hline Variety & Sampling time & Treatments & Single fruit weight $(\mathrm{g})$ & TSS (\%) & TAA (\%) \\
\hline \multirow{14}{*}{ 'Shenhua' } & \multirow{3}{*}{$58 \mathrm{DAA}$} & $\mathrm{N}$ & $11.53 \pm 0.61 \mathrm{a}$ & $13.70 \pm 0.10 \mathrm{a}$ & $3.70 \pm 0.11 \mathrm{a}$ \\
\hline & & W & $11.40 \pm 1.00 \mathrm{a}$ & $11.73 \pm 0.12 b$ & $3.98 \pm 0.27 \mathrm{a}$ \\
\hline & & s & $11.73 \pm 0.23 \mathrm{a}$ & $11.73 \pm 0.12 b$ & $3.90 \pm 0.08 \mathrm{a}$ \\
\hline & \multirow{3}{*}{$72 \mathrm{DAA}$} & $\mathrm{N}$ & $13.53 \pm 0.50 \mathrm{a}$ & $16.53 \pm 0.06 \mathrm{a}$ & $1.73 \pm 0.07 \mathrm{~b}$ \\
\hline & & W & $12.93 \pm 0.42 \mathrm{a}$ & $16.00 \pm 0.17 \mathrm{~b}$ & $1.85 \pm 0.19 \mathrm{ab}$ \\
\hline & & s & $11.67 \pm 0.58 a$ & $13.67 \pm 0.06 c$ & $2.05 \pm 0.11 \mathrm{a}$ \\
\hline & \multirow{3}{*}{$85 \mathrm{DAA}$} & $\mathrm{N}$ & $12.00 \pm 0.40 \mathrm{a}$ & $16.97 \pm 0.06 \mathrm{a}$ & $1.41 \pm 0.02 \mathrm{a}$ \\
\hline & & W & $12.07 \pm 0.70 \mathrm{a}$ & $16.23 \pm 0.06 \mathrm{~b}$ & $1.39 \pm 0.04 a$ \\
\hline & & s & $12.67 \pm 0.31 \mathrm{a}$ & $15.23 \pm 0.21 \mathrm{c}$ & $1.38 \pm 0.11 \mathrm{a}$ \\
\hline & \multirow{5}{*}{$91 \mathrm{DAA}$} & $\mathrm{N}$ & $13.60 \pm 0.69 \mathrm{a}$ & $17.53 \pm 0.06 a$ & $1.35 \pm 0.04 a$ \\
\hline & & W & $13.93 \pm 0.50 \mathrm{a}$ & $16.10 \pm 0.10 \mathrm{bc}$ & $1.33 \pm 0.11 \mathrm{a}$ \\
\hline & & s & $13.60 \pm 0.53 \mathrm{a}$ & $15.83 \pm 0.06 \mathrm{c}$ & $1.43 \pm 0.10 \mathrm{a}$ \\
\hline & & WT & $13.87 \pm 0.42 \mathrm{a}$ & $16.67 \pm 0.06 \mathrm{~b}$ & $1.36 \pm 0.10 \mathrm{a}$ \\
\hline & & ST & $13.53 \pm 0.64 a$ & $16.23 \pm 0.38 \mathrm{~b}$ & $1.50 \pm 0.04 \mathrm{a}$ \\
\hline \multirow{14}{*}{ 'Shenfeng' } & \multirow{3}{*}{$58 \mathrm{DAA}$} & $\mathrm{N}$ & $9.67 \pm 0.12 \mathrm{a}$ & $12.17 \pm 0.06 \mathrm{a}$ & $4.95 \pm 0.13 a$ \\
\hline & & W & $8.13 \pm 0.42 a$ & $11.43 \pm 0.06 \mathrm{~b}$ & $4.75 \pm 0.04 a$ \\
\hline & & s & $9.60 \pm 0.20 \mathrm{a}$ & $11.43 \pm 0.06 \mathrm{~b}$ & $4.03 \pm 0.04 \mathrm{~b}$ \\
\hline & \multirow{3}{*}{$72 \mathrm{DAA}$} & $\mathrm{N}$ & $10.33 \pm 0.70 \mathrm{a}$ & $17.97 \pm 0.06 \mathrm{a}$ & $2.25 \pm 0.20 \mathrm{a}$ \\
\hline & & W & $10.27 \pm 0.12 \mathrm{a}$ & $16.43 \pm 0.06 \mathrm{~b}$ & $2.23 \pm 0.04 a$ \\
\hline & & s & $10.33 \pm 0.31 \mathrm{a}$ & $15.60 \pm 0.17 \mathrm{c}$ & $2.15 \pm 0.04 \mathrm{a}$ \\
\hline & \multirow{3}{*}{$85 \mathrm{DAA}$} & $\mathrm{N}$ & $10.80 \pm 0.35 a$ & $18.10 \pm 0.03 a$ & $1.71 \pm 0.23 \mathrm{a}$ \\
\hline & & W & $11.80 \pm 0.72 \mathrm{a}$ & $16.43 \pm 0.06 \mathrm{~b}$ & $1.51 \pm 0.11 b$ \\
\hline & & $\mathrm{s}$ & $11.33 \pm 0.23 \mathrm{a}$ & $16.17 \pm 0.06 c$ & $1.50 \pm 0.10 \mathrm{~b}$ \\
\hline & \multirow{5}{*}{$93 \mathrm{DAA}$} & $\mathrm{N}$ & $10.73 \pm 0.81 \mathrm{a}$ & $19.63 \pm 0.06 \mathrm{a}$ & $1.25 \pm 0.06 \mathrm{~b}$ \\
\hline & & W & $12.07 \pm 0.12 \mathrm{a}$ & $16.50 \pm 0.10 \mathrm{~b}$ & $1.40 \pm 0.04 \mathrm{a}$ \\
\hline & & S & $11.33 \pm 0.50 \mathrm{a}$ & $16.93 \pm 0.32 \mathrm{~b}$ & $1.38 \pm 0.02 \mathrm{a}$ \\
\hline & & WT & $12.20 \pm 0.20 \mathrm{a}$ & $16.90 \pm 0.30 \mathrm{~b}$ & $1.30 \pm 0.04 \mathrm{~b}$ \\
\hline & & ST & $11.33 \pm 0.81 \mathrm{a}$ & $17.10 \pm 0.10 \mathrm{~b}$ & $1.28 \pm 0.08 \mathrm{~b}$ \\
\hline
\end{tabular}

Different lower case letters indicate significant differences $(P<0.05)$

DAA 58

N

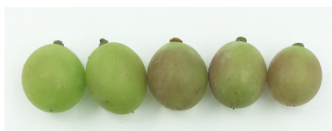

W

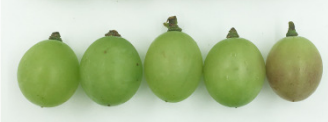

S

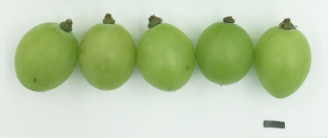

DAA 72

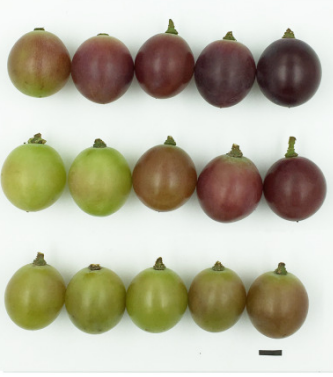

DAA 85

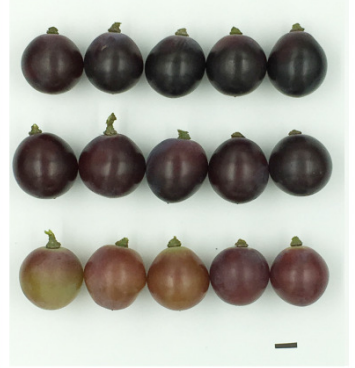

Fig. S1. Fruit grains of 'Shenhua' from 58 DAA to 85 DAA. N: no bag treatment; W: white bag treatment; S: shading bag treatment $(\mathrm{Bar}=1 \mathrm{~cm})$

DAA 58

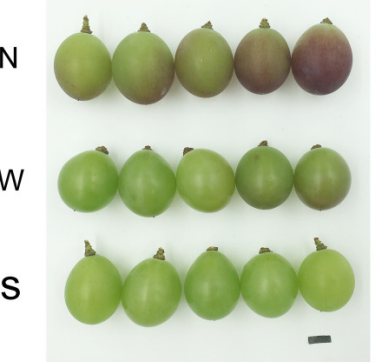

DAA 72

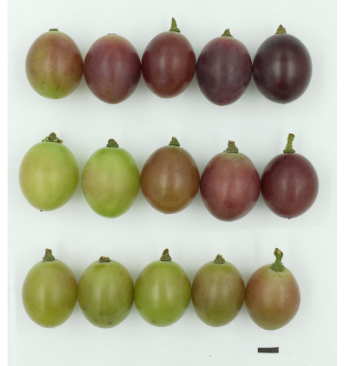

DAA 85

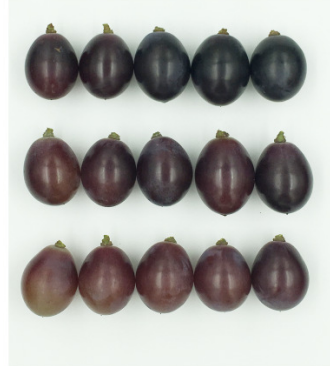

Fig. S2. Fruit grains of 'Shenfeng' from 58 DAA to 85 DAA. N: no bag treatment; W: white bag treatment; S: shading bag treatment $(\mathrm{Bar}=1 \mathrm{~cm})$ 